\title{
Consumer and Community Pharmacists' Perceptions of Online Pharmacy Services in Uyo Metropolis, Nigeria
}

Ekpedeme Ndem ${ }^{1}$; Arit Udoh ${ }^{2}$; Olajide Awofisayo ${ }^{1}$; Enitome Bafor ${ }^{3}$

${ }^{1}$ University of Uyo, Akwa Ibom State, Nigeria; ${ }^{2}$ University College London, London, United Kingdom;

${ }^{3}$ University of Benin, Edo State, Nigeria

\begin{abstract}
Background: Online pharmacies benefit consumer healthcare experience through affording convenience, efficiency, greater confidentiality, and improved access to medicines. There are several online pharmacies in Nigeria, however, studies about their use as well as consumer and pharmacists' perceptions of the service are lacking.

Objective: This study aimed to evaluate community pharmacists' and consumer perceptions of online pharmacy services (OPS) in Uyo metropolis, Nigeria.

Method: This was a cross-sectional survey involving community pharmacists and consumers. The survey instrument was a structured, self-administered questionnaire. Survey data was analysed descriptively using frequencies and percentages while $X^{2}$ was used to evaluate association between variables.

Results: In total, 60 community pharmacists and 500 consumers replied to the survey. Although the majority (>85\%) of the survey respondents reported frequent internet use, only about a third (28\%) of the consumers and $57 \%$ of the pharmacists were aware of the availability of online pharmacy services in Nigeria. In general, majority of the consumers were positive about using online pharmacies with approximately two thirds (67\%) indicating that they would consider purchasing medicines from the service in future. Also, $83 \%$ of the consumers indicated that access to online drug information and medicine advice via the service will be valuable. There was a significant $(P<0.05)$ association between consumers' online shopping behaviour and their likelihood to use the service. Also, majority (92\%) of the community pharmacists in this survey agreed that online pharmacies promote pharmaceutical care and this perceived need was associated with their likelihood to provide the service in future $(p=0.002)$. Consumer concerns about the service included the risk of substandard and counterfeit medicines, internet security, unavailability of prescribed brands, chances of ordering wrong medicines and uncertainty about timely delivery.

Conclusion: Overall awareness of the availability of online pharmacy services in Nigeria is limited in the survey population despite reported frequent internet use in this cohort. Generally, our findings suggest the potential for future uptake of online pharmacy services and highlight the need for a standardised approach to service provision as well as a regulatory framework to improve consumer confidence and alleviate the concerns raised.
\end{abstract}

Keywords: online pharmacy, community pharmacy, consumer perceptions, Nigeria

\section{Introduction}

Changing consumer behaviour, advancement in information technology and accessible internet are some of the key drivers for the advent of virtual healthcare services including online pharmacies $^{1,2}$. Globally, year-on-year increases in online purchases of consumer goods and services that comprise a significant proportion of medicines and health-related products have been reported in the literature ${ }^{2}$. In countries in SubSahara Africa (SSA), estimates indicate rising five-year growth in number of internet users ranging from $35-50 \%{ }^{3}$. This rise in internet accessibility has facilitated a boom in e-commerce in SSA countries including Nigeria and also provide opportunities that can be harnessed to improve access to essential health services via the use of information technology ${ }^{4,5}$.

\section{Corresponding author: Ekpedeme Ndem}

Faculty of Pharmacy, University of Uyo

Akwa Ibom State, Nigeria

Email: ekpedemendem@uniuyo.edu.ng
Online pharmacies refer to internet-based vendors of medicines and health-related goods and services. These services offer key advantages that include convenience and efficiency, competitive pricing, accessibility, privacy and doorstep delivery with no limits on geographic proximity unlike in traditional "brick and mortar" pharmacies ${ }^{6,7}$. However, illegal dispensing of prescription-only drug products, poor quality, adulterated and substandard medications, misleading drugrelated information and advertisement, as well as the unregulated manner of functioning are some of the key challenges of online pharmacy services reported in the literature ${ }^{8-11}$. Although online pharmacies exist in Nigeria and some SSA countries, information on their scope, regulation and benefit is unavailable in the literature.

Evidence from published literature suggest that online pharmacies strengthen collaboration between pharmacists and the communities served ${ }^{12,13}$. Reports show that virtual counselling and consultation services provide an avenue for tracking and strengthening pharmacovigilance in remote health centers and hard-to-reach communities ${ }^{14}$. The findings of 
existing studies and systematic reviews indicate that these services may enhance accessible and participatory medication prescribing that promote treatment adherence with quality care interventions and outcomes ${ }^{15,16}$. Although information on the benefit of online pharmacies is unavailable for Nigeria; some of the advantages of these services reported in other countries are likely to be transferrable given the broader context of the impact of enhanced pharmaceutical services on patient and health outcomes. This is of particular importance in countries such as Nigeria with challenges related to medicines access and availability of essential health services. However, studies show that the awareness of the existence of online pharmacy services and the perceptions of health practitioners as well as the public may promote or hinder this service. While research on consumer perceptions of online pharmacy services have been published; this evidence in lacking for most of the countries in SSA. This study aims to assess pharmacists' and consumer perceptions of online pharmacy services in Nigeria.

\section{Method}

This study was conducted in Uyo metropolis, the capital of Akwa Ibom State in Nigeria. The study setting was chosen based on access to contact persons, time constraints and available resources. This was a cross-sectional survey of community pharmacists and patrons of the 72 registered pharmacies in Uyo metropolis. The study was conducted from August to October 2018 and involved a combination of purposive and random sampling technique. Community pharmacists were sampled purposively with the superintendent pharmacist in each of the 72 pharmacies in Uyo invited to participate. Given that the total population of consumers who utilize community pharmacies in Uyo metropolis was unknown, the population size was assumed to be large $(>100,000)$ in the Epi Info sample size calculator (version 7). The outcome of the calculation showed a sample size of 384 at a $5 \%$ error margin and $95 \%$ confidence interval, assuming $50 \%$ of the population responded. Based on this and to allow for attrition, 10 patrons per pharmacy were randomly selected and invited to participate via a simple random sampling technique.

\section{Study questionnaire}

The self-administered questionnaire used in this research was adapted from a validated instrument developed in previous research by Sah and colleagues ${ }^{17}$. In adapting the questionnaire, two questions about internet usage were added. Questions about respondents' concerns and risk perceptions were merged for brevity and to reflect the practice context in Nigeria. "Part $A$ " of the questionnaire was for community pharmacists while "Part B" was designed for consumers of community pharmacy services. Part A and B of the survey instrument comprised five sections (A-E) each. Section A obtained demographic information (age, gender, qualification) while sections $B, C, D$, and $E$ collected information on internet usage, level of awareness of online pharmacies, perceptions of respondents towards online pharmacies, respectively. The questionnaire items comprised a combination of closed and multiple-choice questions. The adapted questionnaire was pretested for face validity in five pharmacists and consumers each and internal consistency assessed via Cronbach's Alpha (CA). The pre-test showed the questions were judged appropriate and representative of the construct of interest thereby confirming face validity. The analysis for internal consistency showed CA of 0.91 and 0.89 for questions 1-5 that measured internet usage, and 0.87 and 0.90 for questions $6-10$ that measured awareness and likelihood to offer online pharmacy services, in Part A and B of the questionnaire, respectively. The data from this pre-testing were not included in the final analysis.

\section{Data analysis}

Survey responses obtained from fully completed questionnaires were analysed using the Statistical Package for the Social Sciences (SPSS) version 22. Descriptive statistics that included frequencies and percentages was used to quantify demographic data as well as the responses related to awareness and perceptions. Inferential analysis using the Pearson's Chi-Square $\left(X^{2}\right)$ was conducted to evaluate the relationship between respondents' medicine purchase preferences, pharmacists' perceived need and likelihood to offer online pharmacy services.

\section{Ethical consideration}

Ethics approval was granted for the study by the Association of Community Pharmacists of Nigeria (ACPN), Akwa Ibom State Branch. Included in the study were adults ( $\geq 18$ years old) who were literate. Respondents' confidentiality was maintained by using anonymised data. The respondents also completed the questionnaire in a private section within the respective pharmacies. Completed questionnaire were stored in locked filling cabinet at the Faculty of Pharmacy, University of Uyo, Nigeria. Study participation was voluntary, and respondents were informed that they could opt-out of the study at any time. Willingness to complete the questionnaire was taken as consent to participate.

\section{Results}

\section{Demographics}

In total, 60 pharmacists and 500 consumers fully completed Part $A$ and $B$ of the questionnaire, respectively. Table 1 shows the demographics for the study sample. 
Table 1: Sample Demographics

\begin{tabular}{|c|c|c|c|}
\hline & & $\begin{array}{c}\text { Pharmacists } \\
\text { N (\%) }\end{array}$ & $\begin{array}{c}\text { Consumers } \\
\mathrm{N}(\%)\end{array}$ \\
\hline \multirow{2}{*}{ Gender } & Male & $39(65)$ & $255(51)$ \\
\hline & Female & $21(35)$ & 245 (49) \\
\hline \multirow{4}{*}{ Age (years) } & $18-30$ & $30(50)$ & $338(68)$ \\
\hline & $31-40$ & $17(28)$ & 94 (19) \\
\hline & $41-50$ & $8(13)$ & 45 (9) \\
\hline & $>50$ & $5(8)$ & $23(5)$ \\
\hline \multirow{3}{*}{$\begin{array}{l}\text { Highest Level } \\
\text { of Education }\end{array}$} & Primary & - & $16(3.2)$ \\
\hline & Secondary & - & $105(21)$ \\
\hline & Tertiary & 60 (100) & $379(76)$ \\
\hline \multirow{2}{*}{$\begin{array}{l}\text { Length of } \\
\text { pharmacy } \\
\text { practice } \\
\text { experience } \\
\text { (vears) }\end{array}$} & $0-5$ & $37(62)$ & - \\
\hline & $>5$ & $23(38)$ & - \\
\hline & N Total & 60 & 500 \\
\hline
\end{tabular}

\section{Respondents' Internet usage}

Majority of the respondents in the pharmacist and consumer cohort reported that they use the internet, have access to internet-enabled mobile phones/devices and are active on social media (Figure 1). However, compared to the pharmacists' cohort, only about $40 \%$ of the consumers had purchased an item online prior to the survey. Overall, internet usage was not associated with respondents' age, gender or education level $(p \geq 0.5)$ in either cohort.

Figure 1: Respondents' Internet Usage

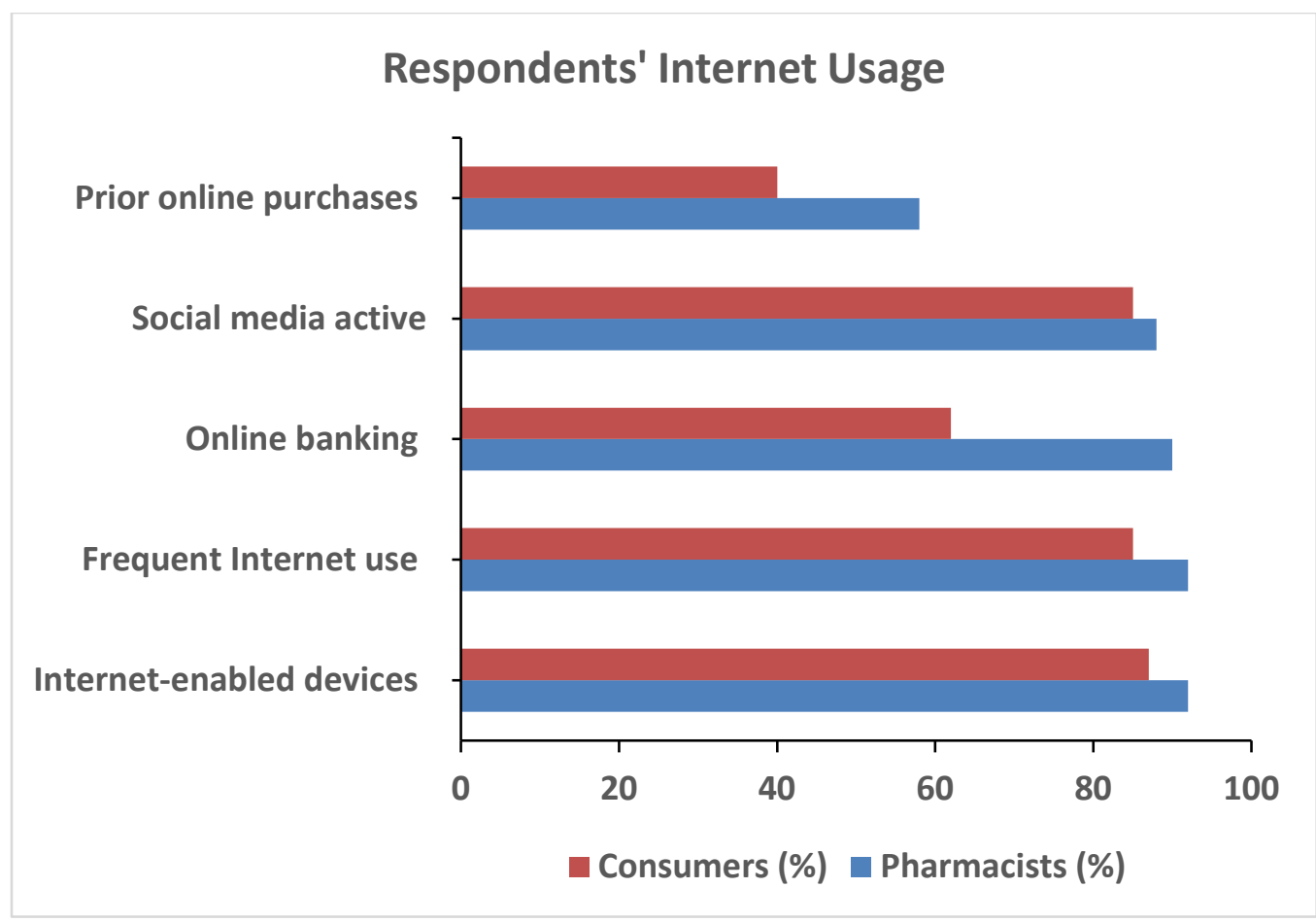


Consumers' awareness, perceptions and concerns about service

Less than a third of the consumers in this survey were aware of the availability of online pharmacy services in Nigeria (Table 2). There was also an association between having purchased an item online prior to the survey and consumers' plan to use online pharmacy services in the future $\left(X^{2}=18.5, p=0.001\right)$. Although majority $(\mathrm{N}=337,67 \%)$ of the consumers agreed that online pharmacy services were good, about third dissented to this question. Consumers who agreed that online pharmacies services were good reported greater confidentiality, convenience, door step delivery and access to drug information as reasons for their perception (Table 2). The majority of those who dissented reported concerns with substandard and counterfeit medicines, illegal websites and internet security, non-availability of brands prescribed by the physician and chances of ordering wrong medicines (Table 2). Uncertainty about timely delivery of medicines was also reported as a concern for this service.

Table 2: Consumers' awareness, perceptions and concerns about online pharmacies

\begin{tabular}{|c|c|c|}
\hline & ITEM & N (\%) \\
\hline $\begin{array}{l}\text { Awareness and } \\
\text { willingness to use } \\
\text { service }(n=500)\end{array}$ & $\begin{array}{l}\text { Prior purchases from online pharmacy } \\
\text { Awareness of online pharmacies in Nigeria } \\
\text { Would like access to online drug } \\
\text { information/medicine advice services } \\
\text { Willingness to purchase from online } \\
\text { pharmacies in the future }\end{array}$ & $\begin{array}{l}15(3) \\
141(28) \\
97(60) \\
337(67)\end{array}$ \\
\hline $\begin{array}{l}\text { Perceptions about } \\
\text { service }(n=337)\end{array}$ & $\begin{array}{l}\text { Offer competitive pricing } \\
\text { Provide easy access to drug information } \\
\text { Advantage of door step delivery } \\
\text { Offer greater confidentiality } \\
\text { Are convenient }\end{array}$ & $\begin{array}{l}156(46) \\
297(88) \\
300(89) \\
314(93) \\
330(98)\end{array}$ \\
\hline $\begin{array}{l}\text { Concerns with service } \\
(n=163)\end{array}$ & $\begin{array}{l}\text { Risk of substandard and counterfeit medicines } \\
\text { Illegal websites and internet security } \\
\text { Non-availability of specified brands of } \\
\text { medicines needed } \\
\text { Delivery of wrong medicines } \\
\text { Issues with timely delivery }\end{array}$ & $\begin{array}{l}111(68) \\
153(94) \\
89(55) \\
97(60) \\
56(34)\end{array}$ \\
\hline
\end{tabular}

Pharmacists' awareness, perceived need and likelihood to offer service

Majority ( $\mathrm{N}=55,91.7 \%)$ of the pharmacists in this survey agreed that online pharmacy services are needed and indicated that they will be willing to provide this service to clients in the future. Pharmacists who agreed or dissented were required to provide reasons for their views. Those who agreed reported low overhead cost, larger market penetration and greater convenience for clients as reasons for their perceptions (Table 3). Those who dissented reported concerns with substandard and counterfeit medicines, internet security and poor internet penetration as well as chances of supplying wrong medicines. There was also an association between pharmacists' perceived client need and likelihood to provide the service in future $\left(X^{2}=\right.$ 9.4, $p=0.002$ ). 
Table 3: Pharmacists' awareness, perceptions and concerns about online pharmacy services

\begin{tabular}{|c|c|c|}
\hline & ITEM & N (\%) \\
\hline $\begin{array}{l}\text { Awareness and } \\
\text { willingness to offer } \\
\text { service }(n=60)\end{array}$ & $\begin{array}{l}\text { Awareness of online pharmacies in Nigeria } \\
\text { Prior purchases from service } \\
\text { Willingness to offer service } \\
\text { Online pharmacies promote pharmaceutical care }\end{array}$ & $\begin{array}{r}34(56.7) \\
6(10) \\
44(73) \\
55(92)\end{array}$ \\
\hline $\begin{array}{l}\text { Perceptions about } \\
\text { service }(n=55)\end{array}$ & $\begin{array}{l}\text { Lower overhead cost } \\
\text { Provide larger market penetration } \\
\text { Greater convenience for clients }\end{array}$ & $\begin{array}{l}46(83) \\
51(93) \\
37(68)\end{array}$ \\
\hline $\begin{array}{l}\text { Concerns with service ( } \mathrm{n} \\
=5 \text { ) }\end{array}$ & $\begin{array}{l}\text { Substandard and counterfeit medicines } \\
\text { Internet security } \\
\text { Poor internet penetration } \\
\text { Chances of supplying wrong medicines }\end{array}$ & $\begin{array}{l}4(80) \\
2(40) \\
2(40) \\
1(20)\end{array}$ \\
\hline
\end{tabular}

\section{Discussion}

The rise in online purchases of consumer goods including medicines and health commodities is likely to continue with increasing digitalisation and proliferation of mobile internet globally ${ }^{2,18,19}$. This trend provides opportunities for innovative models that can revolutionize the way healthcare is delivered via the use of information technology ${ }^{20}$. Although emerging studies from other countries indicate general low awareness of online pharmacy services; the findings of these studies also show consumer willingness to utilise online pharmacy services in the near future ${ }^{1,17,21,22}$. This was also observed in our study where despite the frequent internet usage reported by the survey respondents; our findings demonstrate overall low awareness of online pharmacy services in Nigeria. This finding was also reflected in responses that showed that less than half of the consumers had ever purchased an item online. Although this corroborates the findings of studies that demonstrate general low awareness of the service in other countries including Saudi Arabia ${ }^{23}$, China ${ }^{1}$, Hungary ${ }^{24}$, Romania ${ }^{25}$ and $\mathrm{USA}^{26,27}$; it however underscores the need for measures that would increase awareness of this service. The low awareness of online pharmacy services in the consumer cohort in our study may be related to the comparatively low uptake of e-commerce activities in SSA countries including Nigeria as reported by existing literature ${ }^{3,28}$. Generally, studies of consumer online shopping behaviour in Nigeria show that customers tend to access retailers' online services mainly for information purposes while continuing to shop in traditional stores and malls ${ }^{4,28}$. This feature highlights opportunities that can be harnessed with respect to the provision of online drug information and medicines advice services by pharmacists.

On the other hand, the limited uptake of e-commerce linked to poor internet infrastructure, e-payment challenges and concerns about internet security in the country ${ }^{4}$ emphasizes the need for strategies that would address these issues. This can potentially serve to promote the use of online pharmacy services in the country, especially in view of literature that show that consumers' perceived risk of the service hinders or promotes its uptake ${ }^{29}$. The finding that majority of the survey respondents in the consumer cohort plan to use the service suggest increased future uptake and corroborates the results from existing literature ${ }^{22}$. As the most accessible healthcare providers in many countries including Nigeria, studies show that patients depend on pharmacists for recommendation or choice of legitimate online pharmacies ${ }^{29}$. Therefore, community pharmacist's level of awareness and perception towards online pharmacy service will likely influence their willingness to provide and promote such services. Studies show that social media can promote awareness of online pharmacy services, however, these platforms have also been exploited by illegal pharmacy websites ${ }^{9}$. There is therefore a need for robust regulations and guidelines in relation to online direct to consumer advertisement (DTCA) of pharmaceuticals and health commodities. This is particularly important for countries such 
as Nigeria, where published literature have highlighted the limitation of existing regulations around DTCA ${ }^{30}$.

Although most of the consumers in this survey expressed positive views about online pharmacy services, the concerns raised in this study that include cybersecurity, substandard and falsified medicines, and uncertainty about delivery have also been reported in studies from other countries ${ }^{1,2,6,31}$. This finding highlights the need for a standardized approach to service provision as well as a regulatory framework that would improve consumer confidence in online pharmacies. In USA for example, regulation that certify online pharmacies have been introduced. This includes the Verified Internet Pharmacy Practice Sites (VIPPS) program of the National Boards of Pharmacy and the BeSafeRx campaign of the U.S Food \& Drug Administration ${ }^{32,33}$. The former provides assurance that the online pharmacy meets the country's nationally endorsed standards of pharmacy practice while the latter is a database that can be assessed to confirm the authenticity of an online pharmacy registered in the USA. In a similar certification program introduced in the United Kingdom by the Royal Pharmaceutical Society of Great Britain; certified online pharmacies can display a logo on their websites to provide a measure of assurance of quality of their services ${ }^{34}$. Even though online pharmacies exist in Nigeria, information on whether these meet the pharmacy practice standards of the country and overall regulation is currently lacking. Given that most of our survey respondents indicated interest in purchasing medicines online; there is now an urgent need to provide formal regulatory control over these services in Nigeria.

This study has certain limitations. The survey was conducted in Uyo, metropolis and may not be generalizable to consumers and community pharmacists from other parts of the country. Also, majority of the survey respondents were aged $30-$ 35 years, an age range that have been shown to be more internet savvy and willing to use online shopping services ${ }^{2,35}$. Our study was a cross-sectional survey and relied on survey respondents providing information about their past behavior and interactions with online pharmacy services. Recall and nonresponse bias associated with cross-sectional surveys are key limitations given that these findings may not be representative of the target population ${ }^{36}$. Despite these limitations, our study addresses gaps in the literature about online pharmacy services in Nigeria. Our findings provide important insights that was previously lacking on perceptions and consumer concerns about online pharmacies as well as pharmacists' willingness to provide the service in Nigeria.

\section{Conclusion}

The findings of this study demonstrate overall low awareness of the availability of online pharmacy services in the survey population despite reported frequent internet use in this cohort. Generally, our findings suggest potential increase in uptake of online pharmacy services in Uyo metropolis. This highlights the need for a standardised approach to service provision as well as a regulatory framework to improve consumer confidence and alleviate the concerns raised about online pharmacy services in the country.

Acknowledgment: The authors will like to thank the Association of Community Pharmacists, Akwa Ibom State Branch for their assistance with this project.

\section{Conflict of interest: None declared}

\section{Funding: None}

\section{References}

1. Chen X. The Current Status and Development Countermeasures of Online Pharmacies in China. Open J Soc Sci. 2018;06:224. doi:10.4236/jss.2018.64019

2. KPMG. The Truth about Online Consumers: The 2017 Global Online Consumer Report. KPMG International; 2017:1-40.

https://assets.kpmg/content/dam/kpmg/xx/pdf/2017 /01/the-truth-about-online-consumers.pdf. Accessed January 16, 2019.

3. Abosse Akue-Kpakpo. Study on International Internet Connectivity in Sub-Saharan Africa. A Report of the Regulatory and Market Environment Division (RME) of the Telecommunication Development Bureau and ITU-T Study Group 3. Geneva, Switzerland: International Telecommunication Union; 2013:1-58. https://www.itu.int/en/ITU-D/RegulatoryMarket/Documents/IIC_Africa_Final-en.pdf. Accessed October 12, 2017.

4. Aminu S. Challenges Militating against Adoption of Online Shopping in Retail Industry in Nigeria. J Mark Manag. 2013:12.

5. Marful WA, Winter A. When Information Technology meets Healthcare in West Africa: A Literature Review. J Health Inform Afr. 2014;2(2). doi:10.12856/JHIA2014-v2-i2-104

6. Chaturvedi AK, Singh UK, Kumar A. Online pharmacy: A e-strategy for medication. Int J Pharm Front Res. 2011;1(1):146-158.

https://www.researchgate.net/publication/23720148 1_ONLINE_PHARMACY_AN_ESTRATEGY_FOR_MEDICATION. Accessed January 17, 2019.

7. Orizio G, Merla A, Schulz PJ, Gelatti U. Quality of online pharmacies and websites selling prescription drugs: a systematic review. J Med Internet Res. 2011;13(3):e74-e74. doi:10.2196/jmir.1795

8. Arruñada B. Quality Safeguards and Regulation of Online Pharmacies. Health Econ. 2003:29. 
9. Mackey TK, Nayyar G. Digital danger: a review of the global public health, patient safety and cybersecurity threats posed by illicit online pharmacies. Br Med Bull. 2016;118(1):110-126. doi:10.1093/bmb/ldw016

10. National Association of Boards of Pharmacy. Social Media Sites: The New Wild West for Illegal Online Pharmacies. National Association of Boards of Pharmacy. https://nabp.pharmacy/social-media-sitesthe-new-wild-west-for-illegal-online-pharmacies/. Published October 1, 2018. Accessed January 21, 2019.

11. Sarfaroj Khan. Online pharmacies selling antibiotics without prescription. J Antimicrob Chemother. 2017. https://www.univadis.co.uk/viewarticle/onlinepharmacies-selling-antibiotics-without-prescription492027. Accessed January 22, 2019.

12. Desai C. Online pharmacies: A boon or bane? Indian J Pharmacol. 2016;48(6):615-616. doi:10.4103/02537613.194865

13. Mills D. Cybermedicine: The Benefits and Risks of Purchasing Drugs Over The Internet. J Technol Law Policy. 2000;5(2):15. https://scholarship.law.ufl.edu/cgi/viewcontent.cgi?a rticle $=1001 \&$ context $=$ jtlp.

14. Tambo E, Anyorigiya T, Matimba A, Adedeji A. Digital pharmacy and pharmacovigilance ecosystem in Africa: Perceptions and opportunities. Eur J Pharm Med Res. 2016;3(1):84-90.

https://www.researchgate.net/publication/28883509 5_DIGITAL_PHARMACY_AND_PHARMACOVIGILANCE _ECOSYSTEM_IN_AFRICA_PERCEPTIONS_AND_OPPO RTUNITIES. Accessed January 22, 2019.

15. Duru OK, Schmittdiel JA, Dyer WT, et al. Mail-order pharmacy use and adherence to diabetes-related medications. Am J Manag Care. 2010;16(1):33-40.

16. Schmittdiel JA, Karter AJ, Dyer W, Chan J, Duru OK. The Safety and Effectiveness of Mail Order Pharmacy Use in Diabetes Patients. Am J Manag Care.

2013;19(11):882-887.

https://www.ncbi.nlm.nih.gov/pmc/articles/PMC427 8640/. Accessed January 24, 2019.

17. Sah RK, Chandane RD, Suranagi U, Manocha S, Kapur A. Awareness and behavioural outlook towards online pharmacy services among consumers in Delhi, India: a pilot survey. Eur J Pharm Med Res. 2018;5(3):6. http://www.ejpmr.com/admin/assets/article_issue/1 520135288.pdf.

18. Bhavnani S, Narula J, Sengupta P. Mobile technology and the digitization of healthcare. Eur Heart J. 2016;37(18):1428-1438. https://www.ncbi.nlm.nih.gov/pmc/articles/PMC491 4890/. Accessed July 27, 2019.
19. Shankar V, Venkatesh A, Hofacker C, Naik P. Mobile Marketing in the Retailing Environment: Current Insights and Future Research Avenues. J Interact Mark. 2010;24(2):111-120. doi:DOI: 10.1016/j.intmar.2010.02.006

20. Deloitte. The Impact of Digitalisation on Patient Experience: A Journey towards Health. Luxembourg: Delliotte; 2018:1-24.

https://www2.deloitte.com/content/dam/Deloitte/lu /Documents/life-sciences-health-care/lu_journeysmart-health-digitalisation.pdf.

21. Abanmy N. The extent of use of online pharmacies in Saudi Arabia. Saudi Pharm J SPJ Off Publ Saudi Pharm Soc. 2017;25(6):891-899. doi:10.1016/j.jsps.2017.02.001

22. Fittler $A$, Vida RG, Káplár M, Botz L. Consumers Turning to the Internet Pharmacy Market: CrossSectional Study on the Frequency and Attitudes of Hungarian Patients Purchasing Medications Online. J Med Internet Res. 2018;20(8). doi:10.2196/11115

23. Alfahad NF, Albelali M, Khurshid F, Al-Arifi M, AlDhawailie A, Alsultan A. Perception and Knowledge to Online Pharmacy Services among Consumers in Riyadh, Saudi Arabia: a Pilot Survey. Lat Am J Pharm. 2015;34(6):1113-1118.

https://fac.ksu.edu.sa/fkhurshid/publication/148734. Accessed February 20, 2019.

24. Fittler A, Lankó E, Brachmann B, Botz L. Behaviour analysis of patients who purchase medicines on the internet: can hospital pharmacists facilitate online medication safety? Eur J Hosp Pharm Sci Pract. 2013;20(1):8-12. doi:10.1136/ejhpharm-2012-000085

25. Pal S, Laszlo K, Andras F, et al. Attitude of patients and customers regarding purchasing drugs online. Farmacia. 2015;63(1):93-98.

http://www.revistafarmacia.ro/201501/art-15Szekely_93-98.pdf.

26. Atkinson NL, Saperstein SL, Pleis J. Using the internet for health-related activities: findings from a national probability sample. J Med Internet Res. 2009;11(1):e4. doi:10.2196/jmir.1035

27. Brown J, Li C. Characteristics of online pharmacy users in a nationally representative sample. J Am Pharm Assoc JAPhA. 2014;54(3):289-294. doi:10.1331/JAPhA.2014.13169

28. Ayo CK, Adewoye JO, Oni AA. Business-to-consumer e-commerce in Nigeria: Prospects and challenges. Afr J Bus Manag. 2017;5(13):5109-5117. https://pdfs.semanticscholar.org/51cd/5f35d64355b 60e7bc2e7c6d9b17eb41c0dca.pdf. Accessed February 21, 2019.

29. Hertig J, Anderson C, Scott C, Marwitz K, Walters K, Wasynczuk J. Evaluation of the risk perceptions associated with online pharmacy use. 2017. 
30. Eze A. A review of the advertisement restraint provisions in Nigerian drug laws. Int J Bus Law Res. 2016;4(1):1-8. http://seahipaj.org/journals-ci/mar2016/IJBLR/full/IJBLR-M-1-2016.pdf. Accessed July 27, 2019.

31. Raine C, Webb DJ, Maxwell SRJ. The availability of prescription-only analgesics purchased from the internet in the UK. Br J Clin Pharmacol.

2009;67(2):250-254. doi:10.1111/j.1365-

2125.2008.03343.x

32. National Association Boards of Pharmac y. The Verified Internet Pharmacy Practice Sites (VIPPS) program. National Association of Boards of Pharmacy. https://nabp.pharmacy/programs/vipps/. Published 1999. Accessed February 24, 2019.

33. U.S. Food \& Drug Administration. BeSafeRx: Know Your Online Pharmacy. Buying Medicines Over the Internet.

https://www.fda.gov/Drugs/ResourcesForYou/Consu mers/BuyingUsingMedicineSafely/BuyingMedicinesO verthelnternet/BeSafeRxKnowYourOnlinePharmacy/u cm318487.htm. Published 2017. Accessed February 24, 2019.

34. General Pharmaceutical Council. Guidance for registered pharmacies providing pharmacy services at a distance, including on the internet. 2019. https://www.pharmacyregulation.org/sites/default/fi les/document/guidance_for_registered_pharmacies_ providing_pharmacy_services_at_a_distance_includi ng_on_the_internet_april_2019.pdf.

35. Lassitsa S, Kol O. Generation X vs. Generation Y - A decade of online shopping. J Retail Consum Serv. 2016;31:304-312.

https://www.researchgate.net/publication/30183213 5_Generation_X_vs_Generation_Y__A_decade_of_online_shopping. Accessed February 24, 2019.

36. Sedgwick $P$. Cross sectional studies: advantages and disadvantages. BMJ. 2014;348(g2276).

doi:10.1136/bmj.g2276 